\title{
Two new supramolecular compounds induced by novel vinylpyridine cationic templates: synthesis, structures and enhanced photocatalytic properties
}

\author{
MIN XIAO, SU-MIN LI and YUN-YIN NIU* (D) \\ College of Chemistry and Molecular Engineering, Zhengzhou University, Henan 450001, \\ People's Republic of China \\ E-mail: niuyy@zzu.edu.cn
}

MS received 11 April 2017; revised 28 July 2017; accepted 29 July 2017; published online 19 September 2017

\begin{abstract}
Two novel complexes $\left\{(\text { Pepy })\left[\mathrm{Cu}_{2}(\mathrm{SCN})_{4}\right]\right\}_{\mathrm{n}} \quad(\mathbf{1})$ and $\left\{(\mathrm{Pepy})\left[\mathrm{Cu}_{2} \mathrm{Br}_{4}\right]\right\}_{\mathrm{n}} \quad(\mathbf{2}) \quad[\mathrm{Pepy}=1-2-$ (Pyridinium-1-yl)-1-ethenyl) pyridinium] based on vinylpyridinium organic cation and cuprous salts have been synthesized and characterized by X-ray diffractometry. Compound $\mathbf{1}$ has a 2D polypseudorotaxane structure and compound 2 presents a 1D chain structure. Furthermore, the thermal gravimetric analysis (TGA), UV-Vis diffuse reflectance spectra, the morphology and the photocatalytic performances were studied carefully. Remarkably, both 1 and $\mathbf{2}$ exhibited good photocatalytic degradation abilities towards some dyes.
\end{abstract}

Keywords. Vinylpyridine template; supramolecule; crystal structures; photocatalytic degradation.

\section{Introduction}

With the development of global industrialization process, the most serious problem threatening human survival and development is focused on the environment pollution, particularly the industrial wastewater with organic pollutants. ${ }^{1-5}$ It is quite difficult to deal with them by the traditional methods because of some potential limitations. Recently, photocatalytic reaction directly using solar energy as the light source to drive the reaction, has become an ideal technology to control environment pollution and for clean energy production. ${ }^{6-9}$ The design, construction and elucidation of inorganicorganic hybrid supramolecular polymers have aroused considerable attention in the context of supramolecular chemistry and photocatalysis fields. Template effect of supramolecular compounds, just like catalysis, can act as another approach to convert basic chemicals into novel and functional materials via weak interaction, especially $\mathrm{H}$-bonds and $\pi-\pi$ interaction. ${ }^{10-14}$ Their intriguing structures and functional properties play an important role in chemical engineering and molecular science. Our group has been devoted to the construction of inorganic-organic hybrid compounds and investigated their photochemical properties. ${ }^{15-17}$ As one of the important branches of organic templates, alkylpyridine bivalent cations containing saturated C-C bonds have been widely studied and a large number of templated supramolecular compounds possessing fascinating architectures (including discrete, 1D, 2D and 3D frameworks) and photocatalytic properties have been reported. ${ }^{18-22}$ However, the cation templates with unsaturated $\mathrm{C}=\mathrm{C}$ bonds together with their usage in supramolecular construction has been rarely reported. ${ }^{23}$ The introduction of $\mathrm{C}=\mathrm{C}$ bonds in supramolecules is conducive to the formation of conjugated systems and may bring more interesting physical and chemical properties.

Herein, we report two new compounds based on vinylpyridinium organic cation (Pepy $=1-2$-(Pyridinium1-yl)-1-ethenyl] pyridinium) and cuprous salts $\mathrm{CuSCN}$ (or $\mathrm{CuBr}$ ), namely, $\left\{\left(\text { Pepy) }\left[\mathrm{Cu}_{2}(\mathrm{SCN})_{4}\right]\right\}_{\mathrm{n}}\right.$ (1) and $\left\{(\text { Pepy })\left[\mathrm{Cu}_{2} \mathrm{Br}_{4}\right]\right\}_{\mathrm{n}}(\mathbf{2})$ which showed novel 1-2D structures and were further characterized by single-crystal X-ray diffraction, infrared spectra (IR), Raman spectra, elemental analyses, BET analyses, powder Xray diffraction (PXRD), scanning electron microscope (SEM), energy dispersive spectroscopy (EDS) and

\footnotetext{
*For correspondence
}

Electronic supplementary material: The online version of this article (doi:10.1007/s12039-017-1360-9) contains supplementary material, which is available to authorized users. 
thermogravimetric (TG) analyses. It is noteworthy that compounds $\mathbf{1}$ and $\mathbf{2}$ show high photocatalytic efficiency in the degradation of methylene blue (MB) and methyl orange (MO) in water under irradiation by $500 \mathrm{~W}$ Xe vapor lamp.

\section{Experimental}

\subsection{Materials and measurements}

The dication (Pepy $)^{2}+($ Scheme 1) was prepared as bromide according to the literature method, ${ }^{24}$ while the other chemicals and solvents were of reagent grade and used as purchased without further purification. The IR spectra were recorded on a Shimadzu IR435 spectrometer $\left(4000-400 \mathrm{~cm}^{-1}\right)$ as $\mathrm{KBr}$ disk. The Raman spectra were recorded on a LabRAM HR Evolution High resolution microscopic Raman spectrometer. Elemental analyses $(\mathrm{C}, \mathrm{H}, \mathrm{S}$ and $\mathrm{N})$ were performed on a Perkin-Elmer 240 elemental analyzer. The UV-Vis diffuse reflectance spectra were measured at UV-Vis-NIR Cary 5000 spectrometer. UV-Vis absorption spectra were obtained using UV-5500 PC spectrophotometer. The photocatalytic measurements were carried out using HANUO-IV chemical reaction apparatus (500 W Xe lamp, Model No. HN-GHXIV, ShangHai Hannuo Instrument Co.). A thermal analyzer (model NETZSCHTG209) was used to record simultaneous TG curves in flowing air of $20 \mathrm{~mL} \cdot \mathrm{min}^{-1}$ at a heating rate of $5^{\circ} \mathrm{C} \cdot \min ^{-1}$ in the temperature range $45-800^{\circ} \mathrm{C}$ using platinum crucibles. All powder patterns were collected on a Philips X-pert X-ray diffractometer at a scanning rate of $4^{\circ} \cdot \mathrm{min}^{-1}$ in the $2 \theta$ range from 5 to $50^{\circ}$ with graphite monochromatized $\mathrm{Cu}-\mathrm{K} \alpha$ radiation $(\lambda=0.15418 \mathrm{~nm})$. The $\mathrm{N}_{2}$ adsorption-desorption isotherms were studied by employing NOVA 2000e (Quantachrome Instruments, USA). The surface areas (SBET) of the Brunauer-Emmett-Teller (BET) model were calculated according to the nitrogen adsorption curves. Pore size distributions were estimated using the Barrett-Joyner-Halenda (BJH) model. The micrographs of crystals of $\mathbf{1}$ and $\mathbf{2}$ were taken by Zeiss Auriga SEM, and chemical element composition was analyzed by Oxford Aztec $\mathrm{X}$-max20 EDS.

\subsection{Synthesis of complexes}

Compounds 1-2 were synthesized by similar methods. $10 \mathrm{~mL}$ solution of Pepy $\left(1 \mathrm{mmol}\right.$ ) in $\mathrm{MeCN} / \mathrm{H}_{2} \mathrm{O}$ (volume ratio of $3: 1$ ) was added to a colorless and transparent solution of

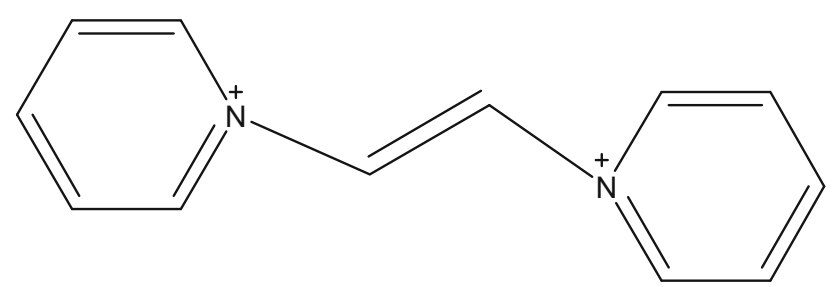

Scheme 1. The molecular structure of the title dication $(\text { Pepy })^{2+}$.
$\operatorname{CuSCN}(0.1216 \mathrm{~g}) / \mathrm{CuBr}(0.1434 \mathrm{~g})(1 \mathrm{mmol})$ dissolved in $10 \mathrm{~mL} \mathrm{MeOH} / \mathrm{H}_{2} \mathrm{O}$ (volume ratio of 3:1) with excess KSCN $(0.3887 \mathrm{~g}) / \mathrm{KBr}(0.4760 \mathrm{~g})$. The resulting mixture was stirred for $10 \mathrm{~min}$ and filtered. Then the solution was slowly evaporated in a glass dish at room temperature.

For compound 1, reddish brown cubic crystals were obtained after 7 days in about $65 \%$ yield based on copper ion. IR $\left(\mathrm{KBr}, \mathrm{cm}^{-1}\right)$ : 3441( $\left.\mathrm{m}, \sigma_{\mathrm{C}=\mathrm{C}-\mathrm{H}}\right), 3076(\mathrm{w}), 2994(\mathrm{w})$, 2098(s), 2079(s), 1625(s, $\left.\sigma_{\mathrm{C}=\mathrm{C}}\right), 1482(\mathrm{~s}), 908\left(\mathrm{~m}, \omega_{\mathrm{C}=\mathrm{C}-\mathrm{H}}\right)$, 775(m), 669(s). Anal. Calcd. for $\mathrm{C}_{8} \mathrm{H}_{6} \mathrm{CuN}_{3} \mathrm{~S}_{2}: \mathrm{C}, 35.32 ; \mathrm{H}$, 2.21; S, 23.59; N, 15.45\%. Found: C, 35.34; H, 2.19; S, 23.56 $\mathrm{N}, 15.43 \%$.

For 2, brown crystals were obtained after 4 days with satisfactory yield $(83 \%)$ based on copper ion. IR $(\mathrm{KBr}$, $\left.\mathrm{cm}^{-1}\right)$ : 3444(w, $\left.\sigma_{\mathrm{C}=\mathrm{C}-\mathrm{H}}\right), 3108(\mathrm{w}), 3037(\mathrm{w}), 1625\left(\mathrm{~s}, \sigma_{\mathrm{C}=\mathrm{C}}\right)$, 1479(s), 1236(m), 908(s, $\left.\omega_{\mathrm{C}=\mathrm{C}-\mathrm{H}}\right), 781(\mathrm{~s}), 673(\mathrm{~s}), 509(\mathrm{~m})$. Anal. Calcd. for $\mathrm{C}_{6} \mathrm{H}_{6} \mathrm{Br}_{2} \mathrm{Cu}_{2} \mathrm{~N}$ : C, 22.82; $\mathrm{H}, 1.90 ; \mathrm{N}, 4.44 \%$. Found: C, 22.80; H, 1.91; N, 4.45\%.

\section{$2.3 X$-ray crystallography}

The crystallographic data for compounds $\mathbf{1}$ and $\mathbf{2}$ were collected on a Bruker SMART CCD diffractometer with graphite-monochromated Mo K $\alpha$ radiation $(\lambda=0.71073 \AA)$ at $293 \mathrm{~K}$. Absorption corrections were applied by using SADABS. The crystal structures of $\mathbf{1}$ and $\mathbf{2}$ were solved by the direct method and refined on F2 by full-matrix least-squares techniques with the SHELXTL-9 $7^{10}$ or OLEX-2 $2^{11}$ program. All the non-hydrogen atoms were refined anisotropically. The hydrogen atoms were assigned with common isotropic displacement factors and included in the final refinement by using geometrical restraints. The key crystallographic information for $\mathbf{1}$ and $\mathbf{2}$ are summarized in Table 1. Selected bond lengths and angles are given in Table S1 (Supplementary Information).

\section{Results and Discussion}

\subsection{Synthesis of complexes}

Compounds $\mathbf{1}$ and $\mathbf{2}$ were prepared by similar methods of solvent evaporation at room temperature. At first, the reaction of $\mathrm{CuSCN}$ inorganic salt and organic cation produced the supramolecular compounds, the reaction process was much fast and resulted in a large amount of precipitate, which made the final crystal yield as low. We tried to use $\mathrm{DMF} / \mathrm{H}_{2} \mathrm{O}$ system to reduce the precipitation, but the crystal growth became very slow. Eventually we chose the $\mathrm{MeCN} / \mathrm{H}_{2} \mathrm{O}$ system, with a small amount of anhydrous methanol to adjust the overall precipitation volume and the volatilization of mixed solvent. To some extent, a satisfying result was reached.

\subsection{Crystal structure of $\mathbf{1}$}

Compound 1 crystallizes in the monoclinic system with space group $\mathrm{P} 2_{1} / \mathrm{c}$. The structure unit and the 
Table 1. Crystal data and structure refinement details for $\mathbf{1}$ and $\mathbf{2}$.

\begin{tabular}{lcc}
\hline Compound & $\mathbf{1}$ & $\mathbf{2}$ \\
\hline Empirical formula & $\mathrm{C}_{8} \mathrm{H}_{6} \mathrm{CuN}_{3} \mathrm{~S}_{2}$ & $\mathrm{C}_{6} \mathrm{H}_{6} \mathrm{Br}_{2} \mathrm{CuN}$ \\
Formula weight & 271.82 & 315.48 \\
Crystal system & monoclinic & monoclinic \\
Space group & $\mathrm{P} 21 / \mathrm{c}$ & $\mathrm{C} 2 / \mathrm{c}$ \\
$\mathrm{a} / \AA$ & $8.2920(16)$ & $15.5295(7)$ \\
$\mathrm{b} / \AA$ & $17.565(3)$ & $9.8047(3)$ \\
$\mathrm{c} / \AA$ & $6.8399(13)$ & $11.0310(4)$ \\
$\alpha(\mathrm{o})$ & 90.00 & 90 \\
$\beta(\mathrm{o})$ & $95.899(2)$ & $97.138(4)$ \\
$\gamma(\mathrm{o})$ & 90.00 & 90 \\
V/Å & $990.9(3)$ & $1666.59(11)$ \\
$\mathrm{Z}$ & 4 & 8 \\
Dc/g cm-3 & 1.822 & 2.515 \\
$\mu /$ mm-1 & 2.583 & 12.131 \\
$\mathrm{~F}(000)$ & 544.0 & 1184.0 \\
Crystal size/mm & $0.2 \times 0.2$ & $0.13 \times 0.12 \times 0.1$ \\
T/K & 296.15 & $293(2)$ \\
Reflections collected & 4515 & 5169 \\
Independent reflections & $1742[\mathrm{Rint}=0.0250, \mathrm{Rsigma}=0.0221]$ & $1707[\mathrm{Rint}=0.0343, \mathrm{Rsigma}=0.0575]$ \\
data/restrains/ parameters & $1742 / 0 / 121$ & $1707 / 0 / 95$ \\
GOF on F2 & 1.069 & 1.000 \\
Final R indices [I>2 $\sigma(\mathrm{I})]$ & $\mathrm{R} 1=0.0397, \mathrm{wR} 2=0.0906$ & $\mathrm{R} 1=0.0406, \mathrm{wR} 2=0.0734$ \\
$\mathrm{R}$ indices (all data) & $\mathrm{R} 1=0.0442, \mathrm{wR} 2=0.0934$ & $\mathrm{R} 1=0.0671, \mathrm{wR} 2=0.0824$ \\
Largest diff. peak & 1.10 & 0.60 \\
hole(e Å-3) & -0.79 & -0.86 \\
\hline & &
\end{tabular}

crystal packing diagram of $\mathbf{1}$ are shown in Figure 1 . Compound 1 possesses a faveolate architecture and is made up of infinite $2 \mathrm{D}$ inorganic $\left[\mathrm{Cu}_{2}(\mathrm{SCN})_{4}\right]_{\mathrm{n}}$ networks with the corresponding cations trapped inside. Each $\mathrm{Cu}$ ion displays a distorted tetrahedral geometry to coordinate with two sulfur atoms $(\mathrm{Cu}-\mathrm{S}(1)=2.453(1)$, $\mathrm{Cu}-\mathrm{S}(2)=2.346(1) \AA)$ and two nitrogen atoms $(\mathrm{Cu}-$ $\mathrm{N}(2)=1.977(3), \mathrm{Cu}-\mathrm{N}(3)=2.002(3) \AA)$ provided by $\mathrm{SCN}$ ligands. The bond angles around the $\mathrm{Cu}(\mathrm{I})$ ion vary from 98.0(1) to 115.6(1) ${ }^{\circ}$, comparable with those found in the alkylpyridine analogue $\left\{(\right.$ bpe $)\left[\mathrm{Cu}_{2}(\mathrm{SCN})_{4}\right\}_{\mathrm{n}}(97.56(4)-$ $\left.121.65(9)^{\circ}\right)$. The difference in bond distance and departure from $109^{\circ} 28^{\prime}$ for an ideal tetrahedron indicate a distorted tetrahedral geometry around the $\mathrm{Cu}$ center (Figure 1a). Two $\mu_{2}$-SCN groups are bound to two adjacent $\mathrm{Cu}$ centers, forming a $\left[\mathrm{Cu}_{2}(\mathrm{SCN})_{2}\right]$ rectangular unit in which the $\mathrm{Cu}$ centers are separated by a distance of 5.171(3) ^. Each inorganic polymeric net is composed of large hexagonal rings, which is formed by sharing four edges and two $\left[\mathrm{Cu}_{2}(\mathrm{SCN})_{2}\right]$ rectangular units and additional bonds with six adjacent hexagonal rings. The $\mathrm{Cu} \cdots \mathrm{Cu}$ separation distances in the hexagonal rings show remarkable variation with short side of 8.495(3) $\AA$ and long side of 13.861(4) $\AA$. Two $\mathrm{Cu}$ ions bridged by single $\mu_{2}-\mathrm{SCN}$ have a distance of
5.819(1) $\AA$ (Figure 1b). The anion structure is similar to $\left\{\right.$ (bpe) $\left[\mathrm{Cu}_{2}(\mathrm{SCN})_{4}\right\}_{n}{ }^{18}$ The Pepy acts as a classical anti-conformation with two parallel pyridyl rings except for the short $\mathrm{C}=\mathrm{C}$ space bond distance $(1.30 \AA)$. In the crystal packing diagram, the Pepy molecules are located in large cavities of the polypseudorotaxane with no unusual short contacts to them. Interestingly, Pepy exhibits two types of perpendicular penetrating modes (Figure 1c). This is not by accident. The perpendicular penetrating modes should be responsible for the undulating polymeric structure. The non-covalent and electrostatic interactions serve as the forces interlinking the inorganic and organic motifs, thus sustaining the architectures.

\subsection{Crystal structure of 2}

Complex 2 crystallizes in monoclinic space group C2/c. In the crystal of compound $\mathbf{2}$, the structure is a 1$\mathrm{D}\left[\mathrm{Cu}_{2} \mathrm{Br}_{4}\right]_{n}^{2 n-}$ polymeric anion chain accompanied by discrete cations. The central $\mathrm{Cu}(\mathrm{I})$ ion was fourcoordination completed via four $\mathrm{Br}$ ions in a typical distorted tetrahedral geometry. The coordination environment of $\mathrm{Cu}(\mathrm{I})$ is as shown in Figure $2 \mathrm{a}$. The $\mathrm{Cu}-\mathrm{Br}$ 
(a)

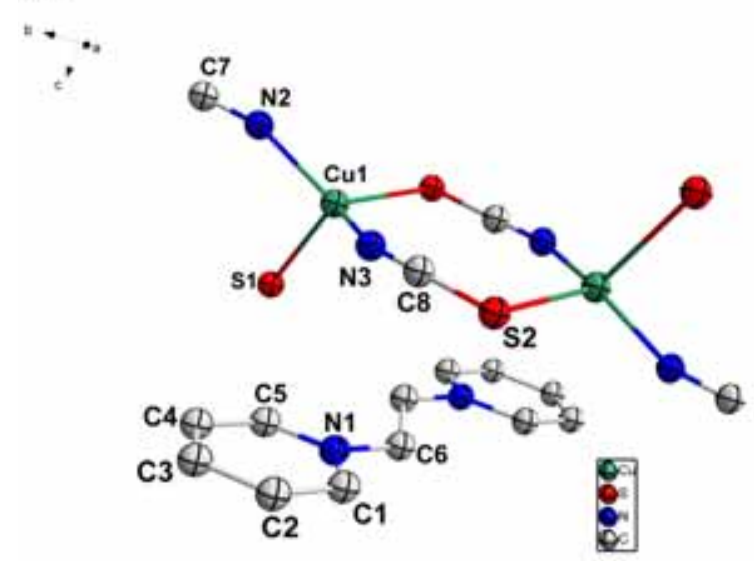

(b)

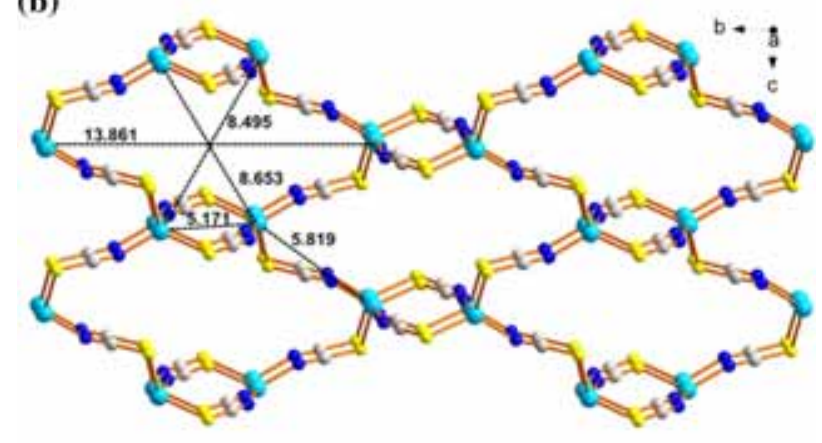

(c)

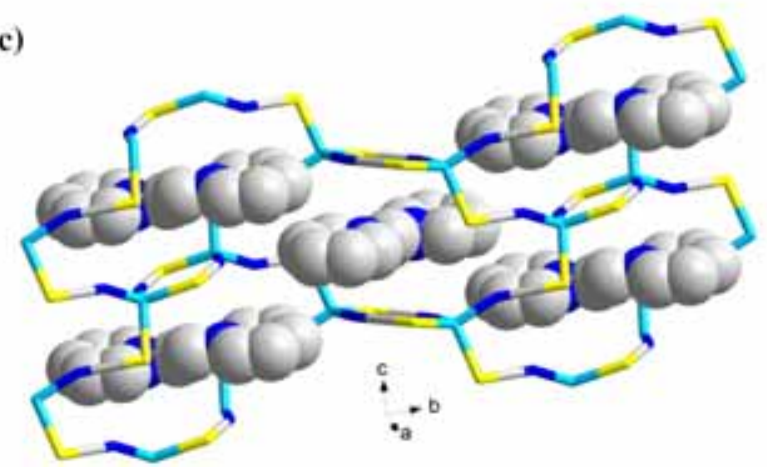

Figure 1. (a) The thermal ellipsoidal plots of compound 1; (b) 2D inorganic polymeric net; (c) Structure showing the polyrotaxane mode of $\mathbf{1}$. The $\mathrm{H}$ atoms were omitted and the others are shown as ball and stick models for clarity.

distances ranged from 2.5004(9) to 2.521(1) $\AA$ and the bond angles of $\operatorname{Br}(1)-\mathrm{Cu}(1)-\operatorname{Br}(2)$ were $111.44(3)$ and 106.50(3) $)^{\circ}, \operatorname{Br}(1)-\mathrm{Cu}(1)-\operatorname{Br}(1)=111.73(3)^{\circ}, \operatorname{Br}(2)-$ $\mathrm{Cu}(1)-\mathrm{Br}(2)=114.04(3)^{\circ}$. As shown in Figure 2b, two adjacent $\mathrm{Cu}$ atoms were bridged by a $\mathrm{Cu} \cdot \mathrm{Cu}$ distance of 2.723(2) and 2.801(2) $\AA$ to form an infinite chain, comparable with those found in the cuprous cluster analogue $\left(\left[\mathrm{Cu}_{5}\left(\mu_{4}-\mathrm{Br}\right)\left(\mu_{3}-\mathrm{Br}\right)_{2}\left(\mu_{2}-\mathrm{Br}\right)_{2}\right]_{5}\left(\mu_{2}-\mathrm{MeSPr}\right)_{3}\right)_{\mathrm{n}}$ $(2.84 \AA)$ and $\left[\mathrm{Cu}_{2} \mathrm{Br}_{4}\right]_{\mathrm{n}}(2.845-2.946 \AA) .{ }^{25,26}$ The packing in space between inorganic and organic moieties is (a)

$\therefore$

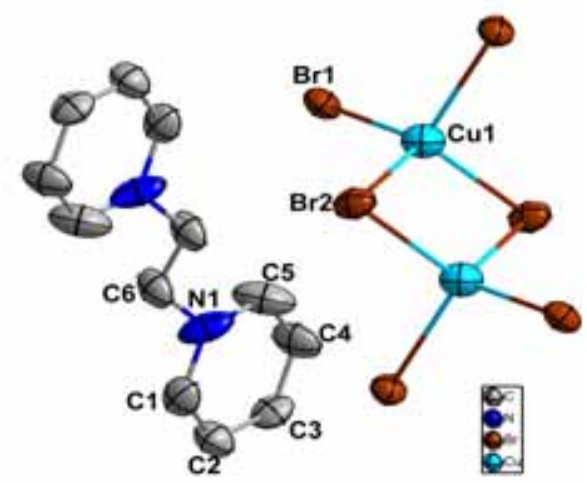

(b)

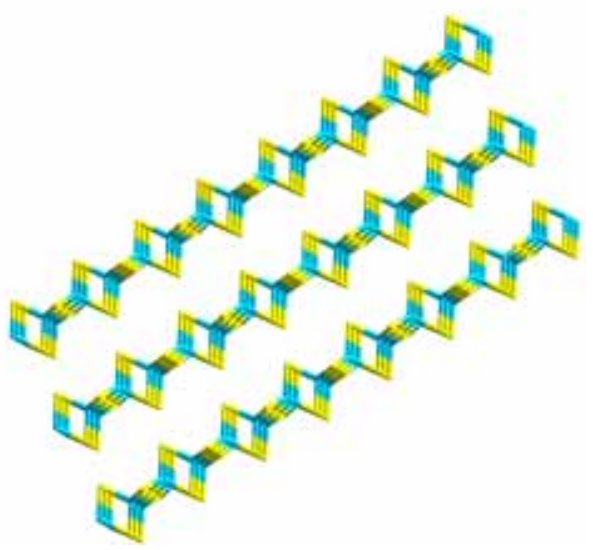

Figure 2. (a) The thermal ellipsoidal plots of compound 2; (b) Structure showing 1D chain structure of $\mathbf{2}$ viewed along the b-direction.

mainly ascribable to the electrostatic force and van der Waals interactions.

\subsection{Other characterizations}

In order to examine the thermal stability of $\mathbf{1}$ and 2, thermal gravimetric (TG) analysis was carried out. The TG curve indicates that $\mathbf{1}$ is thermally stable up to $195^{\circ} \mathrm{C}$ and 2 up to $185^{\circ} \mathrm{C}$. And over the range of $195(185)-797^{\circ} \mathrm{C}$, the successive weight-loss process corresponds to the decomposition of organic cations and inorganic bulks for compounds $\mathbf{1}$ and $\mathbf{2}$ (Figure S4 in SI). The phase purity of $\mathbf{1}$ and $\mathbf{2}$ were confirmed by the corresponding powder X-ray diffraction (PXRD) pattern (Figure S5 in SI). The experimental data and the fitting data agreed exactly, which indicated that the sample is pure. The morphology of crystals $\mathbf{1}$ and $\mathbf{2}$ were observed in the SEM images (Figure 3), which revealed that $\mathbf{1}$ appeared as porous solid and $\mathbf{2}$, rhombic-shaped. EDS survey spectra also showed all the expected elements (Figure 4), in agreement with single crystal X-ray diffraction results. 

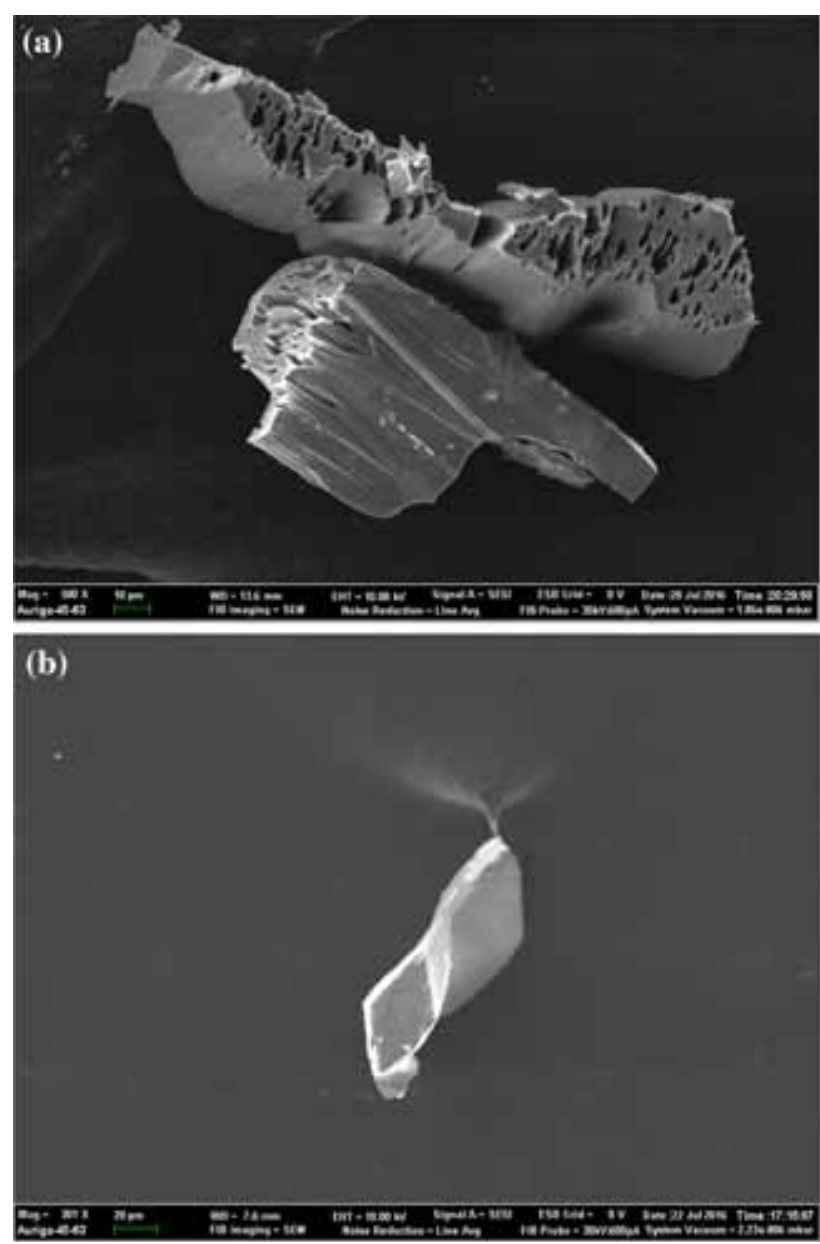

Figure 3. (a) SEM images of compound 1; (b) compound 2.

\subsection{Optical band gap and photocatalytic properties}

The UV-Vis spectra of $\mathbf{1}$ and $\mathbf{2}$ are similar with several obvious peaks in the $200-270 \mathrm{~nm}$ range. Such absorption bands could be assigned to the $\pi-\pi^{*}$ transitions of the aromatic rings in the cations, ${ }^{27}$ as shown in Figure S6 (in Supplementary Information). The band gap $\left(\mathrm{E}_{\mathrm{g}}\right)$ was determined as the intersection point between the energy axis and the line extrapolated from the linear portion of the absorption edge in a plot of Kubelka-Munk function F against energy E. KubelkaMunk function, $F=(1-R)^{2} / 2 R$, was calculated from the recorded diffuse reflectance data, where $\mathrm{R}$ is the reflectance of an infinitely thick layer at a given wavelength. ${ }^{28}$ Extrapolating the linear part of the rising curve to zero provides the onset of absorption at $2.51 \mathrm{eV}$ for $\mathbf{1}$, at $2.45 \mathrm{eV}$ for $\mathbf{2}$, as shown in Figure S7 (in SI). These onset values for absorption show that $\mathbf{1}$ and $\mathbf{2}$ can be regarded as semiconducting materials and employed as potential photocatalysts upon exposure to UV light.

To investigate the photocatalytic activity of complexes $\mathbf{1}$ and $\mathbf{2}$ in detail, we selected aqueous solutions of MB (methylene blue, $1.0 \times 10^{-5} \mathrm{M}, 100 \mathrm{~mL}$ ) and MO (methylene orange, $5.0 \times 10^{-5} \mathrm{M}, 100 \mathrm{~mL}$ ) as models of dyes in water. The compounds $\mathbf{1}\left(50 \mathrm{mg} 1.8 \times 10^{-4} \mathrm{~mol}\right)$ and $2\left(50 \mathrm{mg} 1.5 \times 10^{-4} \mathrm{~mol}\right)$ were added to the $100 \mathrm{~mL}$ $\mathrm{MB} / \mathrm{MO}$ aqueous solution (10 $\mathrm{mg} / \mathrm{L})$, separately. Then magnetically stirred in the dark for $30 \mathrm{~min}$ to ensure equilibrium of adsorption/desorption. The solution was kept under irradiation by a $500 \mathrm{~W}$ Xe lamp continuously stirring with the aid of a magnetic stirrer. $3.0 \mathrm{~mL}$ of sample was taken for analysis. The photodegradation process of $\mathrm{MB}$ and $\mathrm{MO}$ without any catalyst was also studied as the control experiment. ${ }^{29-33}$ The characteristic absorption of $\mathrm{MB}$ and $\mathrm{MO}$ at $\sim 664 \mathrm{~nm}$ (MB) and $\sim 463$ $\mathrm{nm}(\mathrm{MO})$, respectively, were chosen to monitor the photocatalytic degradation process, as shown Figures S8 and S9 (in Supplementary Information). Besides, the concentrations of MB/MO $(\mathrm{C})$ versus reaction time $(\mathrm{t})$ of complexes $\mathbf{1}$ and $\mathbf{2}$ are plotted in Figures 5 and 6 (a)

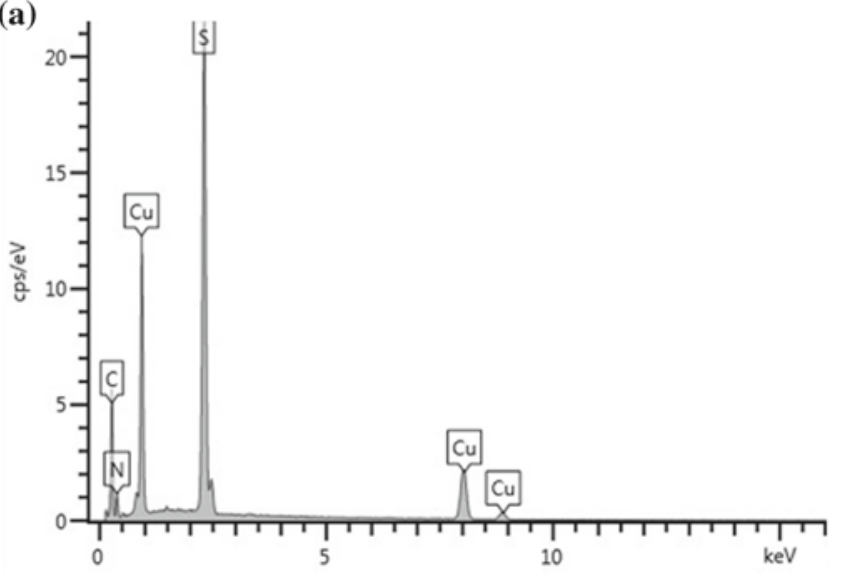

(b)

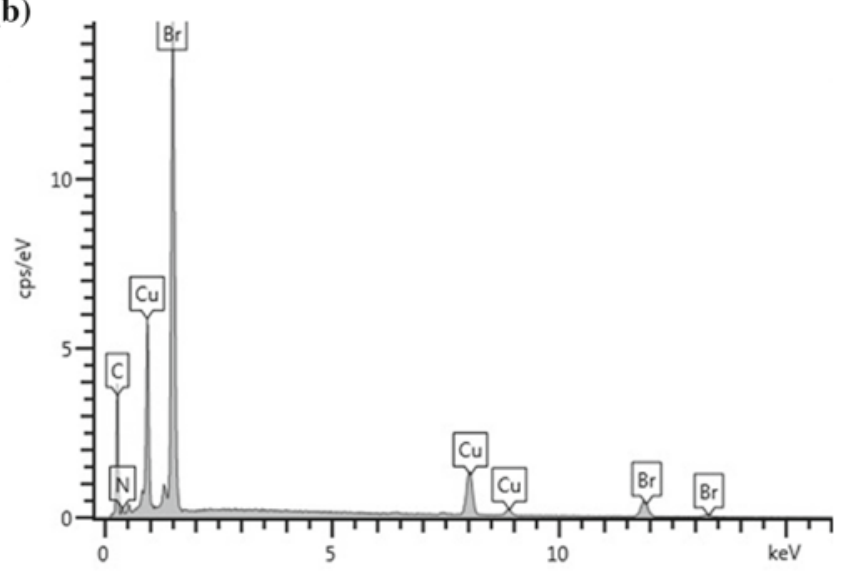

Figure 4. (a) EDS patterns of compound 1; (b) compound 2. 


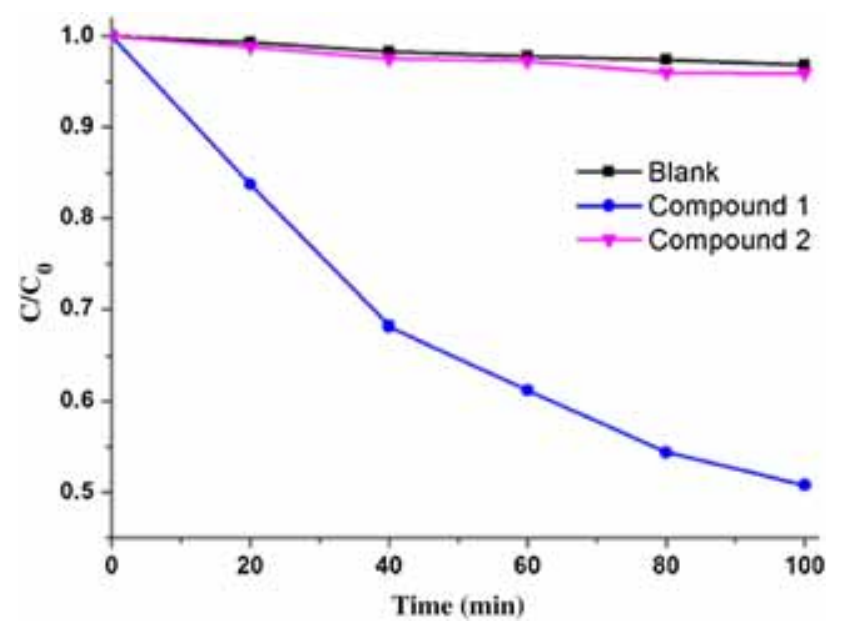

Figure 5. Photocatalytic degradation of MB solution under UV light irradiation by the use of compounds $\mathbf{1}$ and $\mathbf{2}$, and the control experiment (blank) without any catalyst.

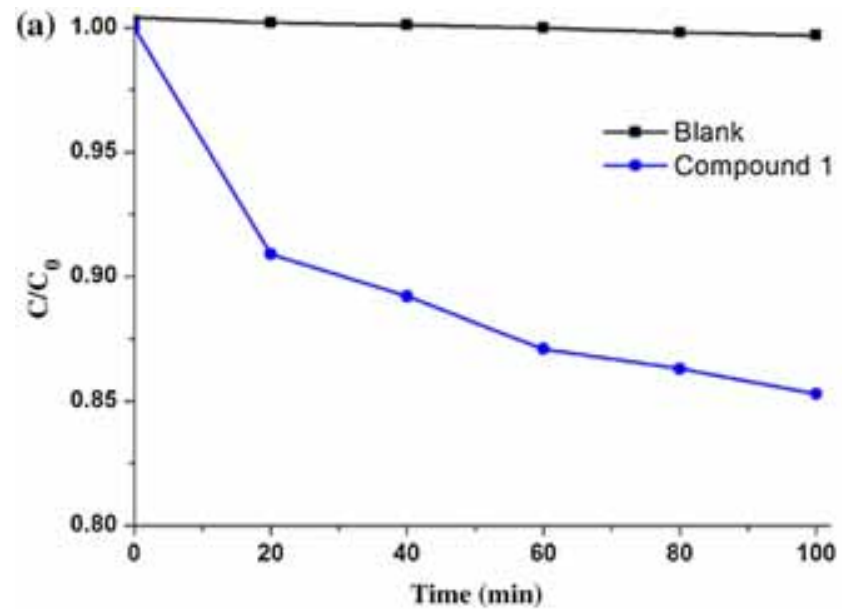

(wherein, $\mathrm{C}_{0}$ is the initial concentration of the $\mathrm{MB} / \mathrm{MO}$ and $\mathrm{C}$ is the concentration of the dye at any given time).

As shown in Figures 5 and 6 and Figures S8 and S9 (Supplementary Information), we can see that complexes $\mathbf{1}$ and $\mathbf{2}$ are vigorous for the decomposition of MB/MO under the UV light irradiation; Pepy had no ability to decompose the dye MO (Figure S10 in SI). For complex 1 approximately $50.8 \%$ of MB and $19.6 \%$ of MO were decomposed after 100 min. For 2, about $6.9 \%$ of MB was decomposed after $100 \mathrm{~min}$. It is noted that more than $74 \%$ of $\mathrm{MO}$ was decomposed during the first 8 min by using compound $\mathbf{2}$ as photocatalyst which is faster than other supramolecular compounds and MOFs reported in recent literature. ${ }^{34-37}$ From the degradation results of MB and MO, it is obvious that complex 1 possessed higher activity for MB and complex 2 possessed higher activity for MO. ${ }^{38,39}$

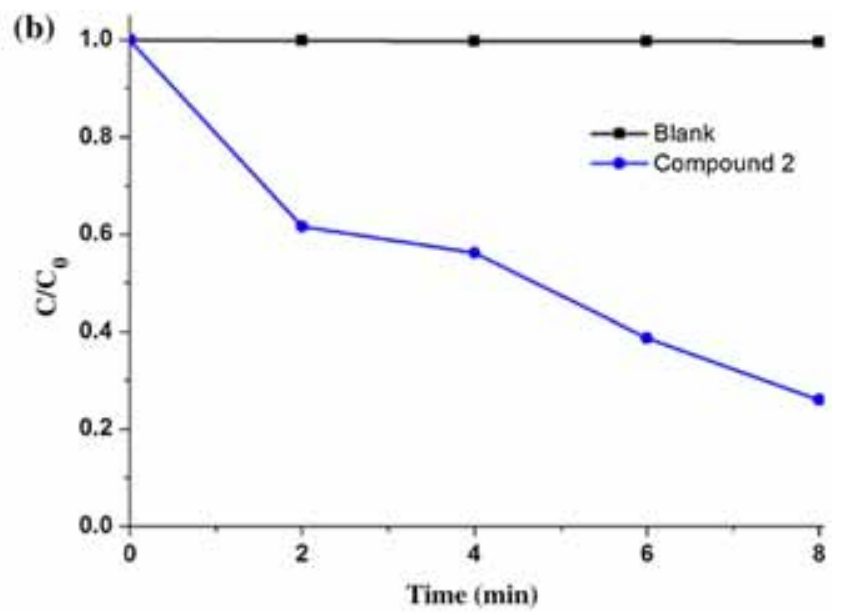

Figure 6. Photocatalytic degradation of MO solution under UV light irradiation by the use of compounds $\mathbf{1}$ and $\mathbf{2}$, and the control experiment (blank) without any catalyst.
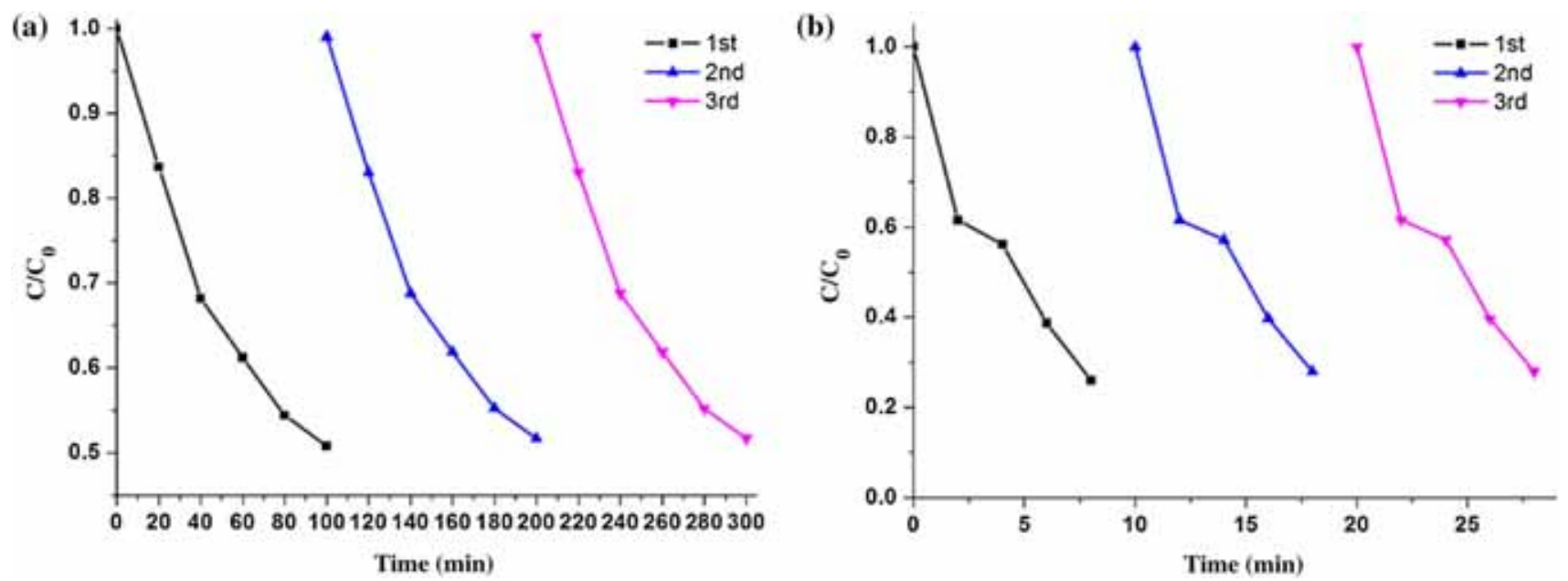

Figure 7. (a) Recycling of complex 1 after MB photodegradation; (b) Recycling of complex 2 after MO photodegradation. 
(a)

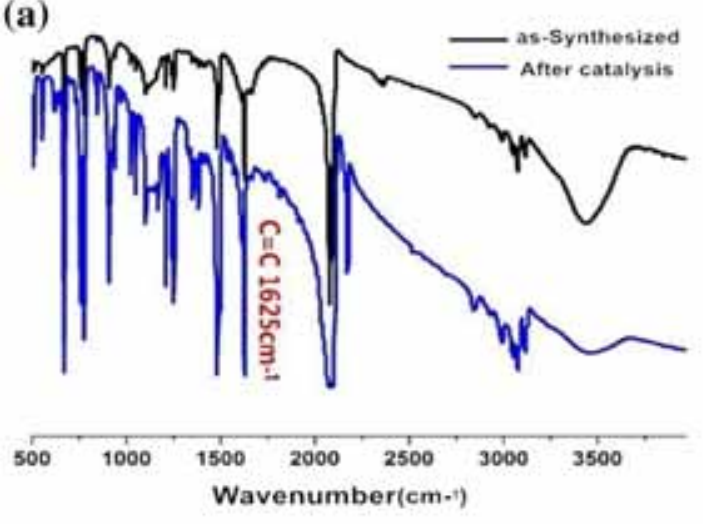

(b)

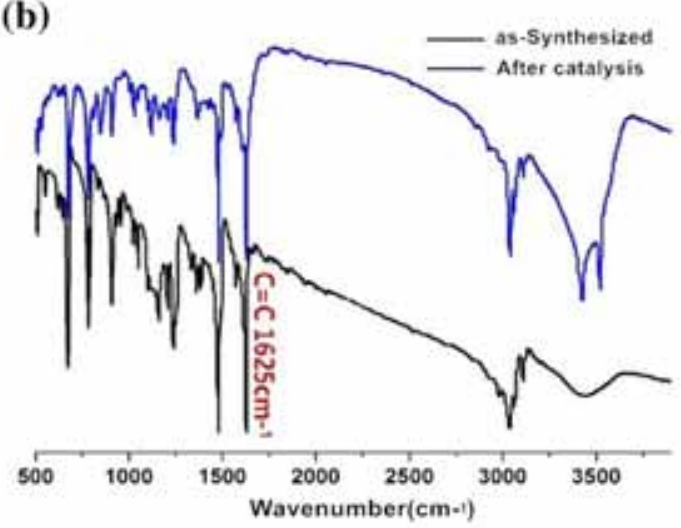

(c)

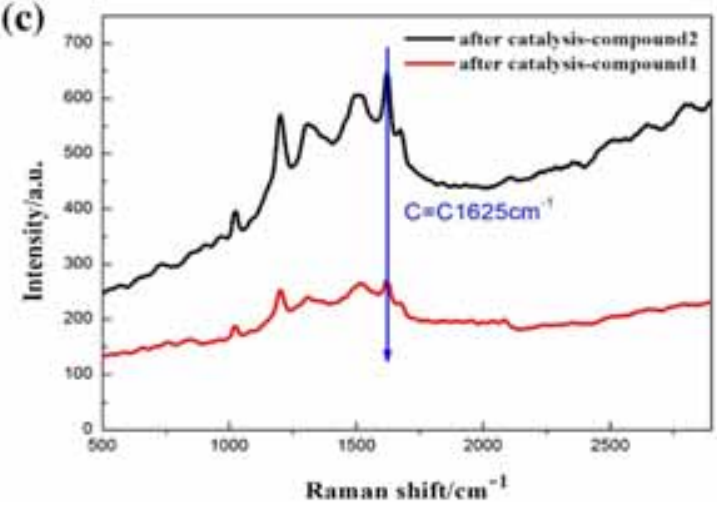

Figure 8. (a) IR spectra of the as-synthesized and solid residue samples of $\mathbf{1}$ after the photocatalytic degradation of MB. (b) IR spectra of the as-synthesized and solid residue samples of $\mathbf{2}$ after the photocatalytic degradation of MO; (c) Raman spectra of $\mathbf{1}$ and $\mathbf{2}$ after use as photocatalyst.

In order to study the photocatalytic mechanism we did the BET test, as shown in Figure S11 (in SI). According to $\mathrm{N}_{2}$ adsorption-desorption isotherms, specific surface area were obtained: $\mathrm{S}_{\mathrm{BET} 1}=2.4841 \mathrm{~m}^{2} / \mathrm{g}$ and $\mathrm{S}_{\text {BET2 }}=1.5043 \mathrm{~m}^{2} / \mathrm{g}$, which were far less than the reported values in the literature. ${ }^{40,41}$ So, they are nonporous materials and their catalytic effect is not due to physical adsorption. According to the related photocatalytic reactions reported in recent years, ${ }^{42-44}$ we think that the photocatalytic mechanism can be deduced as follows: the electrons $\left(\mathrm{e}^{-}\right)$of complexes were excited from the valence band (VB) to the conduction band (CB). The same number of holes $\left(\mathrm{h}^{+}\right)$remained in the valence band. These excited electrons can be captured by $\mathrm{O}_{2}$ to form superoxide radical anion $\cdot \mathrm{O}_{2}^{-}$, while the holes can be captured by $\mathrm{OH}^{-}$to form hydroxide free radical $\cdot \mathrm{OH}$, which are active species for photodegradation of organic dyes. The gradually decreased photocatalytic activity of complexes $\mathbf{1}$ and $\mathbf{2}$ may be related to the width of band gap. Commonly, narrow band gap is conducive to the separation of the charges. Compound $\mathbf{2}$ possesses more significant photocatalytic degradation ability for MO, which could be mainly ascribed to its small band gap. For MO, the degradation rate agrees with $\mathbf{2}>\mathbf{1}$, which is consistent with the theoretical result. However, the degradation rate of $\mathrm{MB}$ does not agree with the order of the band gaps, which may be influenced by the difference in their anion structures. ${ }^{45,46}$ Furthermore, the degeneration mechanism about this system can be related to the interaction between unsaturated bond species and anions in solution. With high activity, $\pi$ bonds act as the bridge facilitating the process of the electronic transition. The excited electron in compounds $\mathbf{1}$ and $\mathbf{2}$ bind to $\mathrm{O}_{2}$ in solution, which will transform into highly active peroxide anions, which are responsible for the oxidation and total degradation of $\mathrm{MB} / \mathrm{MO} \cdot{ }^{37}$ Although a more elaborate mechanism is also under investigation, the aforesaid phenomenon makes known that $\mathbf{1}$ and $\mathbf{2}$ exhibit good photocatalytic activities in the degradation of $\mathrm{MB} / \mathrm{MO}$ under UV irradiation and they may become potential waste-water treatment materials in the future.

To evaluate the stability of the catalysts, recycling of the reactions were carried out for the degradation of MO. In each test, the catalyst was separated from the solution using a centrifugal method. Then, the catalyst was filtered and washed with ethanol and vacuum-dried. As seen in Figures 7 and 8, the catalyst retained its original activity after repeating three times the photocatalytic 
degradation by $\mathbf{1}$ for MB and $\mathbf{2}$ for MO. The Raman spectra and the IR absorption bands of the solid residues left in the reaction mixture after the third time are consistent with those of the two originally synthesized complexes $\mathbf{1}$ and $\mathbf{2}$, which indicate that $\mathbf{1}$ and $\mathbf{2}$ have good stabilities and they can be reused. ${ }^{47}$

\section{Conclusions}

In summary, the use of organic species as templating agents has widened the number and nature of the inorganic crystalline solid phases. The crystal growth can be oriented by the shape and symmetry of the template, ${ }^{48}$ or the size-matching between the cation and anion. ${ }^{49}$ This work has demonstrated a simple method of synthesizing the inorganic-organic hybrid 2D polypseudorotaxane $\left\{(\mathrm{Pepy})\left[\mathrm{Cu}_{2}(\mathrm{SCN})_{4}\right]\right\}_{\mathrm{n}}$ (1) and 1D chain $\left\{(\text { Pepy })\left[\mathrm{Cu}_{2} \mathrm{Br}_{4}\right]\right\}_{\mathrm{n}}(2)$ based on pseudohalides $(\mathrm{CuSCN}$, $\mathrm{CuBr}$ ) and vinylpyridine cationic templates (Pepy). Compounds 1 and $\mathbf{2}$ exhibit good photocatalytic performances and the catalyst was stable and reusable. Considering their high efficiency and high stability on the photocatalytic degradation of organic dyes, these inorganicorganic hybrid materials might be good candidates for photocatalytic applications. This work may pave the way for the preparation of new inorganic-organic hybrid materials with unsaturated bond template and better photocatalytic performances by reasonably designing cationic templates. Further studies in this respect are in progress.

\section{Supplementary Information (SI)}

CCDC reference numbers 1500561-1500562 contain the supplementary crystallographic data for $\mathbf{1}$ and $\mathbf{2}$. These data can be obtained free of charge via http://www.ccdc.cam.ac. uk/conts/retrieving.html, or from the Cambridge Crystallographic Data Centre, 12 Union Road, Cambridge CB2 1EZ, UK; Fax: t44 1223336033 or Email: deposit@ccdc.cam.ac. uk. The IR absorption spectrum of Pepy dibromide; important bond distances and angles for $\mathbf{1}$ and $\mathbf{2}$; experimental and simulated powder XRD patterns; Nitrogen adsorption and desorption isotherms and Pore size distribution; TG plots; the $\mathrm{K}-\mathrm{M}$ function versus energy $(\mathrm{eV})$ curves; absorption spectra of the $\mathrm{MO}$ aqueous solution during the decomposition process with the use of compounds $\mathbf{1}$ and $\mathbf{2}$ and blank; these are available at www.ias.ac.in/chemsci.

\section{Acknowledgements}

Research efforts in the Niu group are supported by the National Science Foundation of China (Nos. 21171148 and 21671177).

\section{References}

1. Naik R, Prashantha S C, Nagabhushana H, Sharma S C, Nagaswarupa H P, Anantharaju K S, Jnaneshwara D M and Girish K M 2016 Tunable white light emissive $\mathrm{Mg}_{2} \mathrm{SiO}_{4}: \mathrm{Dy}^{3+}$ nanophosphor: its photoluminescence, Judd-Ofelt and photocatalytic studies Dyes Pigm. 127 25

2. Song X C, Zheng Y F, Yang E, Liu G, Zhang Y, Chen H F and Zhang Y Y 2010 Photocatalytic activities of $\mathrm{Cd}$-doped $\mathrm{ZnWO}_{4}$ nanorods prepared by a hydrothermal process J. Hazard. Mater. 1791122

3. Lu J C, Liu M C, Zhou S Q, Zhou X and Yang Y G 2016 Electrospinning fabrication of $\mathrm{ZnWO}_{4}$ nanofibers and photocatalytic performance for organic dyes Dyes Pigm. 1361

4. Innocenzia P and Lebeau B 2005 Organic-inorganic hybrid materials for non-linear optics J. Mater. Chem. 153821

5. Yang J L, Yan D H and Jones T S 2015 Molecular Template Growth and Its Applications in Organic Electronics and Optoelectronics Chem. Rev. 1155570

6. Chacon J M, Leal M T, Sanchez M and Bandala E R 2006 Solar photocatalytic degradation of azo-dyes by photo-Fenton process Dyes Pigm. 69144

7. Chouhan A, Pandey A and Mayer P 2015 Synthesis crystal structure, photoluminescence and photocatalytic property of a new three dimensional Zinc(II) tetrazole framework J. Chem. Sci. 1271599

8. Lin $\mathrm{H} \mathrm{Y,} \mathrm{Lu} \mathrm{H} \mathrm{Z,} \mathrm{Le} \mathrm{M,} \mathrm{Luan} \mathrm{J,} \mathrm{Wang} \mathrm{X} \mathrm{L}$ and Liu G C 2015 Three 2 Dcopper(II)/cadmium(II) coordination polymers based on semi-rigid/flexible bis-pyridyl-bis-amide ligands and 5-aminoisophthalate: Syntheses, structures and properties J. Chem. Sci. 127 1275

9. Lin H Y, Sun J J, Liu G C, Wang X and Chen P W 2017 Self-assembly, structures and properties of three new Ni(II) coordination polymers derived from two different bis-pyridyl-bis-amide ligands and two aromatic polycarboxylates J. Chem. Sci. 1299

10. Fustin C A, Guillet P, Schubert U S and Gohy J F 2007 Metallo-supramolecular block copolymers Adv. Mater. 191665

11. Wang R H, Yuan D Q, Jiang F L, Han L, Gong Y Q and Hong M C 2006 Anion Effect on the Structural Conformation of Tetranuclear Cadmium(II) Complexes Cryst. Growth. Des. 61351

12. Lehn J M 2002 Supramolecular polymer chemistryscope and perspectives Polym. Int. 51825

13. Berl V, Schmutz M, Krische M J, Khoury R G and Lehn J M 2002 Supramolecular polymers generated from heterocomplementary monomers linked through multiple hydrogen-bonding arrays-formation, characterization, and properties J. Chem. Eur. 81227

14. Cai L Z, Chen Q S, Zhang C J, Li P X, Wang M S and Guo G C 2015 Photochromism and Photomagnetism of a 3d-4f Hexacyanoferrate at Room Temperature J. Am. Chem. Soc. 13710882

15. Han Y, Zhang Z H, Liu Y, Niu Y, Ding D G, Wu B L, Hou H W and Fan Y T 2011 External TemplateAssisted Self-Assembly:Design and Synthesis of 4,4'bipy-Based $\mathrm{Mo}(\mathrm{W}) / \mathrm{Cu} / \mathrm{S}$ Heterothiometallic Polymeric 
Clusters Directed by 1,1'-Bis(pyridinium)methylene Cation Cryst. Growth. Des. 113448

16. Qiao Y Z, Fu W Z, Yue J M, Liu X C, Niu Y and Hou H W 2012 Role of cooperative templates in the selfassembly process of microporous structures: syntheses and characterization of 12 new silver halide/thiocyanate supramolecular polymers CrystEngComm $\mathbf{1 4}$ 3241

17. Yue J M, Niu Y, Zhang B, Ng S W and Hou H W 2011 Four novel metal coordination polymers directed by $1,1^{\prime}$-dibutyl-4,4'-bipyridinium dibromide (BBP) and their framework dependent luminescent properties CrystEngComm 132571

18. Niu Y, Wu B L, Guo X L, Song Y L, Liu X C, Zhang H Y, Hou H W and Niu C Y 2008 A Systematic Design and Facile Construct of Metal Pseudohalide Frameworks Directed By 1, $\omega$-Bis(pyridinium)alkane Cations Cryst. Growth Des. 82393

19. Wang C H, Du H J, Lu Y B, Xu M M, Wu B L, Niu Y $\mathrm{Y}$ and Hou H W 2016 Bis(3,5-lutidine)alkyl Dications and Their Use in the Fabrication of Organic-Inorganic 2D Polypseudorotaxane by Templated Self-Assembly Cryst. Growth Des. 162487

20. Li H H, Xing Y Y, Lian Z X, Gong A W, Wu H Y, Li Y and Chen Z R 2013 Rigidity/flexibility competition in organic/iodoargentate hybrids: a combined experimental and theoretical study CrystEngComm 151721

21. Sun D, Zhang N, Huang R B and Zheng L S 2010 Series of $\operatorname{Ag}(\mathrm{I})$ Coordination Complexes Derived from Aminopyrimidyl Ligands and Dicarboxylates: Syntheses, Crystal Structures, and Properties Cryst. Growth Des. 103699

22. Lu J, Liu H T, Zhang X X, Wang D Q and Niu M J 2010 Important Roles of Weak Interactions: Syntheses and Supramolecular Structures of Four CoII/NiIIThiocyanato Compounds Z. Anorg. Allg. Chem. 636 641

23. Jia F, Wang H Y, Li D H, Yang L P and Jiang W 2016 Oxatub[4]arene: a molecular "transformer" capable of hosting a wide range of organic cations Chem. Commun. 525666

24. Olegas E L, Gytis K K, Laimute R and Algirdas M 1999 A convenient preparation of 1-vinylpyridinium salts Synthesis 122131

25. Lapprand A, Bonnot A, Knorr M, Rousselin Y, Kubicki M M, Fortin D and Harvey P D 2013 Formation of an unprecedented $(\mathrm{CuBr})_{5}$ cluster and a zeolite-type 2Dcoordination polymer: a surprising halide effect Chem. Commun. 498848

26. Scott B, Willett R, Saccani A, Sandrolini F and Ramakrishna B L 1996 A study of pseudo 1-D copper(I) halide systems exhibiting anomalous copper(II) character: physical characterization of (paraquat) $\mathrm{Cu}_{2} \mathrm{X}_{4}(\mathrm{X}=$ Cl, Br, I) Inorg. Chim. Acta 24873

27. Stadler A M, Puntoriero F, Campagna S, Kyritsakas N, Welter R and Lehn J M 2005 Synthesis, structural features, absorption spectra, redox behaviour and luminescence properties of ruthenium(II) rack-type dinuclear complexes with ditopic, hydrazone-based ligands Chem. Eur. J. 113997

28. Lu C N, Chen M M, Zhang W H, Li D X, Dai M and Lang J P 2015 Construction of Zn(II) and Cd(II) metal-organic frameworks of diimidazole and dicarboxylate mixed ligands for the catalytic photodegradation of rhodamine B in water CrystEngComm 171935

29. Pei J N, Wen S P, Zhou Y H, Dong Q F, Liu Z Y, Zhang J B and Tian W J 2011 A low band gap donoracceptor copolymer containing fluorene and benzothiadiazole units: synthesis and photovoltaic properties $\mathrm{New}$ J. Chem. 35385

30. Du P, Yang Y, Yang J, Liu B K and Ma J F 2013 Syntheses, structures, photoluminescence, photocatalysis, and photoelectronic effects of 3D mixed high-connected metal-organic frameworks based on octanuclear and dodecanuclear secondary building units Dalton Trans. 421567

31. Gao S Y, Cao R, Lu J, Li G, Li Y F and Yang H X 2009 Photocatalytic properties of polyoxometalate-thionine composite films immobilized onto microspheres under sunlight irradiation J. Mater. Chem. 194157

32. Bhat S S M and Sundaram N G 2015 Photocatalysis of $\mathrm{Bi}_{4} \mathrm{NbO}_{8} \mathrm{Cl}$ hierarchical nanostructure for degradation of dye under solar/UV irradiation New J. Chem. 393956

33. Lu Y B, Wang C H and Niu Y Y 2016 Two novel cationinduced supramolecular polymers with 2-3D polymeric cuprous thiocyanate frameworks: Synthesis, characterization and photocatalytic activities for the degradation of organic dye contaminants Inorg. Chim. Acta 450154

34. Wang J L, Wang C and Lin W B 2012 Metal-Organic Frameworks for Light Harvesting and Photocatalysis ACS Catal. 22630

35. Du H J, Wang C H, Li Y, Niu Y Y and Hou H W 2015 Four hybrid compounds based on a new type of molybdates and a flexible tripodal ligand: synthesis, structures, photochemical and electrochemical properties RSC Adv. 574065

36. Hu F L, Shi Y X, Chen H H and Lang J P 2015 A $\mathrm{Zn}$ (II) coordination polymer and its photocycloaddition product: syntheses, structures, selective luminescence sensing of iron(III) ions and selective absorption of dyes Dalton Trans. 4418795

37. Dai M, Li H X and Lang J P 2015 New approaches to the degradation of organic dyes, and nitro- and chloroaromatics using coordination polymers as photocatalysts CrystEngComm 174741

38. Du H J, Zhang W L, Wang C H, Niu Y Y and Hou H W 2016 A new nanocrystalline inorganic-organic hybrid exhibiting semiconducting properties and applications Dalton Trans. $\mathbf{4 5} 2624$

39. Li M, Liu L, Zhang L, Lv X F, Ding J, Hou H W and Fan Y T 2014 Novel coordination polymers of $\mathrm{Zn}$ (II) and Cd(II) tuned by different aromatic polycarboxylates: synthesis, structures and photocatalytic properties CrystEngComm 166408

40. Liu Y, Liu Y, Cheng H S, Yu S C, Nan B, Bian H D, Md K, Wang M, Chung C Y and Lu Z G 2016 Conformal Coating of Heterogeneous $\mathrm{CoO} / \mathrm{Co}$ Nanocomposites on Carbon Nanotubes as Efficient Bifunctional Electrocatalyst for Li-Air Batteries Electrochim. Acta 219560

41. Liu Y Y, Wang S M, Xing C C, Du H, Du C X and Li B J 2016 Nanoporous Carbon Derived from Core-Shells@Sheets through the Template-Activation Method for Effective Adsorption of Dyes ACS Omega 1 491 
42. Chen S, Hu Y, Meng S and Fu X 2014 Study on the separation mechanisms of photogenerated electrons and holes for composite photocatalysts g- $\mathrm{C}_{3} \mathrm{~N}_{4}-\mathrm{WO}_{3} \mathrm{Appl}$. Catal. B Environ. 150564

43. Gong Y, Jiang P G, Wang Y X, Wu T and Lin J H 2013 Metal-organic frameworks based on 1,3,5-triazine-2,4,6triyltrithio-triacetate: structures, topologies, photoluminescence and photocatalytic properties Dalton Trans. 42 7196

44. Wang H L, Zhao L L, Liu X Q, Xu J, Hou W L, Wang J M, He E F, Zhang R J and Zhang H Q 2016 Novel hydrogen bonding composite based on copper phthalocyanine/perylene diimide derivatives $\mathrm{p}-\mathrm{n}$ heterojunction with improved photocatalytic activity Dyes Pigm. 137 322

45. Lu J, Lin J X, Zhao X L and Cao R 2012 Photochromic hybrid materials of cucurbituril and polyoxometalates as photocatalysts under visible light Chem. Commun. 48 669
46. Gong Y, Wu T and Lin J H 2012 Metal-organic frameworks based on naphthalene-1,5-diyldioxy-diacetate: structures, topologies, photoluminescence and photocatalytic properties CrystEngComm 14 3727

47. Wang C H, Du H J, Li Y, Niu Y Y and Hou H W 2015 Crystal structures and photocatalytic properties of two novel iodoplumbate hybrids templated by multivalent organic cations New J. Chem. 397372

48. Soler-Illia G J D A A, Sanchez C, Lebeau B and Patarin J 2002 Chemical Strategies To Design Textured Materials:? from Microporous and Mesoporous Oxides to Nanonetworks and Hierarchical Structures Chem. Chem. Rev. 1024093

49. Garcia M D, Marti-Rujas J, Metrangolo P, Peinador C, Pilati T, Resnati G, Terraneo G and Ursini M 2011 Dimensional caging of polyiodides: cation-templated synthesis using bipyridinium salts CrystEngComm 13 4411 